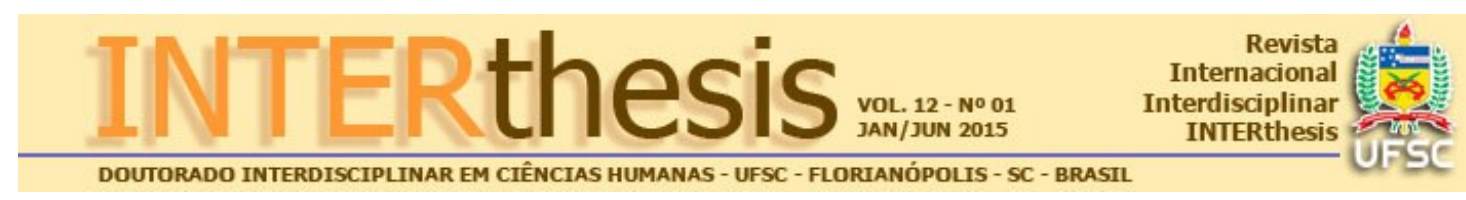

\title{
CONSTRUÇÃO DA CIDADANIA FEMININA: CONTRIBUIÇÕES DO "PACTO NACIONAL PELO ENFRENTAMENTO À VIOLÊNCIA CONTRA A MULHER”
}

\author{
Simone Cristina Dufloth ${ }^{1}$ \\ Mariany Freitas de Oliveira ${ }^{2}$ \\ Maria Isabel Araújo Rodrigues ${ }^{3}$ \\ Rosânia Rodrigues de Sousa ${ }^{4}$
}

\section{Resumo:}

Há alguns anos, vêm sendo elaboradas leis e políticas públicas para amparar a mulher na construção de sua condição de cidadã. Contudo, o avanço na legislação brasileira torna claro que não são mais os aspectos formais que estão inibindo o completo processo de cidadania da mulher. Nesse cenário, é importante discutir quais são, hoje, as melhorias e os desafios vinculados à execução dos direitos garantidos por lei. Ganha destaque aqui a análise dos instrumentos promovidos pelo Poder Público, por intermédio das políticas e ações empreendidas para garantir o exercício de direitos já previstos em lei. Este artigo analisa as principais contribuições do Pacto Nacional pelo Enfrentamento à Violência contra a Mulher e do Plano Estadual de Políticas para Mulheres para a construção da cidadania feminina, em especial do plano adotado pelo estado de Minas Gerais, a partir do entendimento de que se deve averiguar constantemente como os entes federados se mobilizam para enfrentar a temática em questão. A pesquisa configurou-se como de natureza exploratória, desenvolvida a partir de levantamento documental, bibliográfico e de campo. Concluiu-se que, apesar de algumas inciativas incrementais e da existência de diretrizes orientadoras, ainda é inegável a fragilidade da estrutura de enfrentamento à violência contra mulher oferecida pelo Poder Público.

Palavras-chave: Cidadania feminina. Violência contra a mulher. Pacto Nacional pelo Enfrentamento à Violência Contra a Mulher. Plano Estadual de Políticas para Mulheres. Estrutura de enfrentamento à violência contra a mulher.

\footnotetext{
1 Doutora em Ciência da Informação pela Universidade Federal de Minas Gerais. Pesquisadora em Ciência e Tecnologia da Escola de Governo Professor Paulo Neves de Carvalho da Fundação João Pinheiro, em Belo Horizonte, MG, Brasil. Email: sduf@uol.com.br

2 Graduanda em Administração Pública pela Escola de Governo Professor Paulo Neves de Carvalho da Fundação João Pinheiro, de Belo Horizonte, MG, Brasil. Email: marianyfoliveira@hotmail.com ${ }^{3}$ Mestre em Administração Pública pela Escola de Governo Professor Paulo Neves de Carvalho. Coordenadora do Colegiado do Curso de Administração Pública da Escola de Governo Professor Paulo Neves de Carvalho, Belo Horizonte, MG, Brasil. Email: isabel.rodrigues@fjp.mg.gov.br ${ }^{4}$ Doutora em Psicologia Social do Trabalho e das Organizações pela Universidade de Brasília. Pesquisadora plena e docente na Escola de Governo da Fundação João Pinheiro, Belo Horizonte, MG, Brasil. Email: rosania.sousa@fjp.mg.gov.br
}

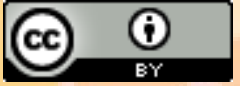
Esta obra foi licenciada com uma Licença Creative Commons - Atribuição 3.0 Não 


\section{INTRODUÇÃO}

A violência contra a mulher é considerada uma violação aos direitos humanos, sobretudo após a instauração de marcos legais de referência, por exemplo, a Convenção Interamericana para Prevenir, Punir e Erradicar a Violência contra a Mulher, ou "Convenção de Belém do Pará", de 9 de junho de 1994. No que tange à Nação, identificam-se a criação da Secretaria de Políticas para as Mulheres, em janeiro de 2003, e o lançamento do Pacto Nacional de Enfrentamento à violência contra mulher, em 2007, que se configurou como importante instrumento de orientação das políticas regionais. No âmbito de Minas Gerais, destacam-se o Plano Estadual de Políticas para Mulheres, em especial o eixo estratégico de enfrentamento de todas as formas de violência contra as mulheres, e a atuação da Coordenadoria Especial de Políticas Públicas para Mulheres (CEPAM).

Com a celebração dos oito anos da Lei 11.340, ou "Lei Maria da Penha" em 7 de agosto, torna-se primordial discutir a temática. Em 2012, a Organização das Nações Ūnidas (ONU) considerou essa lei como a terceira melhor do mundo para o combate à violência doméstica, superada apenas por Espanha e o Chile. Após vários avanços na legislação, é importante discutir as melhorias e os desafios atuais, mesmo que se observe um cenário ainda não muito animador. Levantamento do Instituto de Pesquisa Econômica Aplicada (IPEA) de 2013 revela que Minas Gerais ocupa a segunda posição no ranking dos estados da região Sudeste com o maior número de assassinatos femininos, atrás do Espírito Santo. Torna-se inquestionável, portanto, a necessidade de refletir acerca de políticas públicas. Nesse sentido, é inevitável esbarrar em questões como: intersetorialidade, dificuldades quanto à descentralização, tratamento dos dados e limitações orçamentárias.

\section{PROCEDIMENTOS METODOLÓGICOS}

Para os propósitos deste trabalho, os dados foram obtidos por meio de pesquisa documental e bibliográfica, além de pesquisa de campo, mediante a realização de entrevista e observação pessoal ou direta, com a participação de um dos pesquisadores na $23^{\text {a }}$ Reunião Extraordinária, realizada em junho de 2014, na Assembleia Legislativa de Minas Gerais. Foram coletadas informações que refletem 
a evolução de indicadores sobre violência contra a mulher e as percepções de representantes da CEPAM, da Secretaria de Estado de Desenvolvimento Social de Minas Gerais (SEDESE), com a finalidade de ilustrar o cenário das políticas públicas voltadas para a mulher, a partir da perspectiva da execução de suas ações, especificamente, no que se refere ao enfrentamento da violência.

A pesquisa se fundamentou em uma análise quantitativa e qualitativa da situação estudada, com base na identificação dos principais serviços fornecidos pelo Poder Público para o atendimento da mulher em situação de violência e em sua evolução ao cenário atual. Foram analisadas as informações disponíveis eletronicamente pela Secretaria de Políticas para as Mulheres (SPM), os dados disponibilizados no Mapa da Violência 2012, a Pesquisa de Informações Básicas Estaduais do IBGE de 2012, o Relatório da CPMI de 2013 e o Relatório Final da Comissão Especial da Violência contra a Mulher (MINAS GERAIS, 2012).

$O$ estudo envolveu questionamentos sobre a construção da cidadania feminina no país, os reflexos da violência contra a mulher e os principais eixos estratégicos para seu enfrentamento, discorrendo acerca de seus avanços, entraves e expectativas, sobretudo no que se refere aos equipamentos de atendimento à mulher em situação de violência, concluindo com a ilustração do cenário atual de Minas Gerais.

\section{ENFRENTAMENTO À VIOLÊNCIA CONTRA A MULHER: INICIATIVAS PARA A CONSTRUÇÃO DA CIDADANIA FEMININA}

A discussão sobre as formas de enfrentamento à violência contra a mulher impõe, primeiramente, uma diferenciação entre os termos masculino e feminino. Saffioti (1995) afirma que a única diferença entre homens e mulheres, sob o ponto de vista do sexo, está na constituição genética. Para a autora, as demais diferenças nem são naturais e tampouco sua existência depende da diferença sexual. Ainda segundo a autora, essas diferenças são consideradas construções sociais e caracterizam duas categorias fundamentais presentes na vida em sociedade, a saber, as categorias "Masculino" e "Feminino".

A diferenciação dada a essas duas categorias depende do contexto e da cultura. Portanto, se as relações entre os sexos são apresentadas como definidas 
socialmente, pode-se afirmar que existe uma interdependência entre homens e mulheres. Assim, não há de se falar em relações hierárquicas ou relações de dominação.

Constata-se que a subordinação da mulher ao homem é uma construção histórica e tem sustentação em velhos padrões patriarcais ao longo dos tempos. $O$ conceito de cidadania está muito ligado à ideia de autonomia. Seu exercício pressupõe empoderamento político, social e civil. Partindo da construção teórica desenvolvida por Marshall (1967), a cidadania configura-se pelo conjunto e pelo acesso aos direitos civis, políticos e, por último, sociais. No que se refere à cidadania da mulher, constata-se um atraso em relação ao reconhecimento desses direitos, assim como entraves ao seu exercício. A história evidencia esse atraso. $\mathrm{O}$ direito do voto feminino foi estabelecido em 1932, apesar de seu reconhecimento não se efetivar plenamente pela cultura patriarcal. Ainda em 2010 , apenas $13,02 \%$ dos eleitos para as Assembleias Legislativas estaduais e distritais no Brasil eram mulheres (FJP, 2013). Depreende-se que as questões de gênero ainda demonstram atrasos, por isso devem ser amplamente discutidas.

Em relação ao âmbito civil, em 1916, o Código Civil Brasileiro considerava a mulher como relativamente incapaz, necessitando de apreciação do marido para a validação dos seus atos. Somente em 1962, com a entrada em vigor do Estatuto da Mulher Casada, é que a mulher foi liberada do autoritarismo masculino. A partir de então, sucessivas leis buscaram efetivar as conquistas das mulheres brasileiras, que foram precedidas de grande luta (BICEGLIA, 2002). A Constituição de 1988 reafirma a igualdade da mulher, distanciando-se da influência romana, que, historicamente, atribuiu-Ihe papel social secundário. Preconiza o art. $5^{\circ}$ da Constituição de 1988 que "todos são iguais perante a lei, sem distinção de qualquer natureza, garantindo-se aos brasileiros e aos estrangeiros residentes no País a inviolabilidade do direito à vida, à liberdade, à igualdade, à segurança e à propriedade". Enfatiza, ainda, o inciso primeiro que "homens e mulheres são iguais em direitos e obrigações" (BRASIL, 1988, s.p.).

O avanço na legislação brasileira torna claro que não são mais os aspectos formais que inibem o completo processo de cidadania da mulher. Assim, além da reminiscência de aspectos culturais, é importante avaliar a dificuldade associada à execução dos direitos pela administração pública, a ponto de tornar as conquistas 
legislativas letras mortas. A questão de gênero não pode ser esquecida quando se discorre acerca do acesso pleno à cidadania. Para Arendt (1993), cidadania seria o direito a ter direitos, pressupondo a igualdade. Dessa forma, a cidadania feminina ainda não se apresenta em sua plenitude, seja pela constatação de disparidades salariais, seja, sobretudo, pela violação da dignidade humana, considerando-se a perpetuação das agressões e a constante tentativa de internalizar um sentimento de inferioridade. Entende Benevides (2000) que a participação das pessoas, tanto individualmente como coletivamente, nas mais variadas áreas de atuação da sociedade e na esfera pública é primordial para que haja cidadania. A existência de Conselhos da Mulher, de Conferências de Políticas para Mulheres e de Audiências Públicas pode significar importantes canais de participação ativa do público feminino no desenho e monitoramento das políticas públicas em prol da erradicação da violência e da plena construção da cidadania da mulher. Identificar a existência de tais instituições regionalmente pode explicar como se insere a questão de gênero na agenda pública. Como discorre Soares (2003), para todas as cidadanias fragilizadas ou parciais, como é o caso da feminina, seu processo de construção tem andado de mãos dadas com o da conquista da autonomia. Inevitável, portanto, avaliar como se configura atualmente $\mathrm{o}$ acesso à Justiça, tendo em mente que as mulheres representam 50,80\% da população total de Minas Gerais (IBGE, 2010).

Há alguns anos já vêm sendo construídas políticas para amparar a mulher em sua situação de cidadã. A partir das diretrizes da Política Nacional de Enfrentamento à Violência contra a Mulher, foi lançado, em 2007, o Pacto Nacional pelo Enfrentamento à Violência Contra a Mulher, um acordo federativo pactuado entre o Governo Federal, os governos estaduais e os governos municipais para combater, de forma integrada, a violência contra a mulher, baseando-se inicialmente em quatro eixos/áreas estruturantes: Implementação da Lei Maria da Penha e fortalecimento dos serviços especializados de atendimento; Proteção dos direitos sexuais e reprodutivos e implementação do Plano Integrado de Enfrentamento da Feminização da AIDS; Combate à exploração sexual e ao tráfico de mulheres; e Promoção dos direitos humanos das mulheres em situação de prisão (BRASIL, 2014). A ideia seria abarcar as "dimensões de prevenção, assistência, enfrentamento e garantia dos direitos da mulher" (BRASIL, 2013, p. 44). 
O Pacto prevê a articulação entre os poderes Executivo, Legislativo e Judiciário, no sentido de garantir o atendimento integral e o ciclo completo da política pública de enfrentamento à violência contra as mulheres (SPM, 2014). Considera-se, nesse sentido, que a responsabilidade deve ser assumida por diferentes áreas de governo, como defende o Relatório Final da CPMI de 2013 acerca da violência contra a mulher no País. Importante apontar que todos os estados da federação aderiram ao Pacto. Contudo, a partir de 2011 verificou-se um processo de repactuação, haja vista a ampliação do número de eixos estratégicos para cinco, concretizando uma reestruturação do Pacto, agora visando: a) garantia da aplicabilidade da Lei Maria da Penha; b) ampliação e fortalecimento da rede de serviços para mulheres em situação de violência; c) garantia de segurança à cidadã e acesso à Justiça; d) garantia dos direitos sexuais e reprodutivos, e enfrentamento da exploração sexual e do tráfico de mulheres; e e) garantia da autonomia das mulheres em situação de violência e ampliação de seus direitos (BRASIL, 2013).

O governo de Minas Gerais elaborou o Plano Estadual de Políticas para Mulheres, lançado em 2014. Em resposta às demandas sociais de fortalecimento da cidadania feminina no âmbito estadual, foram são previstos dez eixos estratégicos de atuação: a) Igualdade no mundo do trabalho; b) Educação para igualdade e cidadania; c) Saúde integral das mulheres, direitos sexuais e direitos reprodutivos; d) Enfrentamento de todas as formas de violência contra as mulheres; e) Fortalecimento e participação das mulheres nos espaços de poder e decisão; f) Desenvolvimento sustentável com igualdade econômica e social; g) Direito à terra com igualdade para as mulheres do campo e da floresta; h) Cultura, esporte, comunicação e mídia; i) Enfrentamento do racismo, sexismo e lesbofobia; e j) Igualdade para as mulheres jovens, idosas e mulheres com deficiência. (MINAS GERAIS, 2014).

\section{O PACTO NACIONAL E O PLANO ESTADUAL: PRINCIPAIS EIXOS ESTRATÉGICOS NO ENFRENTAMENTO DA VIOLÊNCIA CONTRA A MULHER}

Com a finalidade de discorrer acerca da estrutura de enfrentamento à violência contra mulher, serão destacados neste trabalho o primeiro e o segundo eixo do Pacto Nacional, além do eixo 4 do Plano Estadual de Políticas para 
Mulheres de Minas Gerais. No eixo I - Garantia da Aplicabilidade da Lei Maria da Penha, o Pacto estabelece como principais ações: a) difusão da lei e dos instrumentos de proteção dos direitos das mulheres, objetivando, primordialmente, a mobilização da sociedade; e a b) implementação da Lei Maria da Penha, defendendo como principais objetivos ampliar o número de juizados e de varas especializadas de violência doméstica e familiar à mulher, de Defensorias Públicas Especializadas/Núcleos da Mulher e da Assistência Judiciária Gratuita, para o atendimento às mulheres em situação de violência e de Promotorias Públicas Especializadas, além dos Núcleos de Gênero, nos Ministérios Públicos Estaduais. Em relação ao eixo II - Ampliação e fortalecimento da Rede de Serviços para Mulheres em Situação de Violência, destacam-se, novamente, as ações referentes a: ampliação dos Serviços Especializados de Atendimento às Mulheres em Situação de Violência e Capilaridade do Atendimento; e b) fortalecimento da Rede de Atendimento para Mulheres em Situação de Violência, preconizando o aumento dos serviços de abrigamento e, de forma geral, dos Serviços Especializados de Atendimento à Mulher em Situação de Violência (BRASIL, 2007).

Alinhadas às diretrizes do Pacto, em relação ao âmbito estatal e a seu eixo 4 Enfrentamento de todas as formas de violência contras as mulheres, podem-se elencar como principais prioridades: ampliação e aperfeiçoamento da Rede de Atendimento às Mulheres em Situação de Violência; e garantia da implementação da Lei Maria da Penha e demais normas nacionais e internacionais que garantam o enfrentamento da violência contra as mülheres e a previsão de potencializar a política pública de abrigamento. Algumas linhas de ação são: incentivo à criação e reestruturação dos Serviços Especializados de Atendimento às Mulheres em Situação de Violência (Delegacias Especializadas no Atendimento à Mulher - DEAM, Casas-abrigo e _.Promotorias, entre outros); e busca por articular e estimular a implementação dos Centros Integrados de Atendimento às Mulheres, além do acompanhamento das ações de implementação dos Juizados de Violência Doméstica, aprovados desde a Lei Complementar 105, de 14 de agosto de 2008. Cabe ressaltar que as metas deste eixo estratégico referem-se, primordialmente, ao reaparelhamento das instituições de apoio à mulher, à mobilização social e à capacitação. 
A partir da assinatura do Pacto, os estados devem elaborar seu Planejamento Integral Básico, contendo: diagnóstico do estado, definição dos municípios-polo, plano para implementação do pacto, especificação dos recursos financeiros necessários e capacidade de Sustentabilidade para as ações. Dessa forma, estimula-se a criação e o fortalecimento de políticas voltadas ao combate da violência contra a mulher (BRASIL, 2007).

Resta saber, contudo, se, de fato, as potenciais influências do Pacto na atuação estatal estão se efetivando no que se refere às estruturas de atendimento, defendidas, primordialmente, nos eixos I e II do Pacto. Na seção seguinte, fazem-se algumas considerações sobre as Unidades Especializadas de Assistência à Mulher em Situação de Violência a partir de dados da Pesquisa de Informações Básicas Estaduais do IBGE de 2012 e do Relatório Final da Comissão Parlamentar Mista de Inquérito de 2013, cujos resultados apontam para algumas dificuldades de atuação dos estados no que se refere à prevenção à violência de gênero. Assim, serão feitas algumas discussões acerca de: administração pública, intersetorialidade de políticas, restrição orçamentária e descentralização.

\section{SERVIÇOS ESPECIALIZADOS DE ATENDIMENTO ÀS MULHERES EM SITUAÇÃO DE VIOLÊNCIA: PRINCIPAIS CONTRIBUIÇÕES DO PACTO E DO PLANO EM MINAS GERAIS}

No relatório final da Comissão Especial da Violência contra a Mulher, publicado pela Assembleia Legislativa de Minas Gerais (MINAS GERAIS, 2012), podem-se elencar várias dificuldades associadas ao combate à violência contra mulher que não caracterizam apenas o cenário mineiro, mas se estendem à realidade nacional. A análise dos documentos da CPMI da Violência Contra a Mulher, disponibilizados pelo Governo Federal, deixa claro que os principais problemas verificados no enfrentamento à violência no que tange às mulheres envolvem o trabalho em rede e questões de ordem orçamentária, que inibem os avanços na infraestrutura e nos recursos humanos envolvidos no processo de combate à violência. Nesse sentido, a efetivação do previsto na Lei Maria da Penha e na Convenção de Belém parece ainda ter pouco impacto nos índices de violência contra a mulher, uma vez que os índices de assassinatos no País foram de 5,28 por 
100 mil mulheres de 2001 a 2006 e de 5,22 no período de 2007 a 2011, depois da implementação da lei (IPEA, 2013).

Para além da discussão sobre o aumento ou diminuição dos índices de homicídios contra as mulheres, uma das representantes da CEPAM em Minas Gerais afirma que é perigoso falar em aumento da violência contra mulher, pois isso pode ser reflexo não só da maior consciência feminina, como também do maior cuidado com o tratamento de dados no estado, representando, assim, contraditoriamente, avanço em relação ao tratamento de dados e à produção de estatísticas. Em consonância com essa colocação, consta no Relatório Final da Comissão Especial de Violência contra a Mulher de 2012 que estudo da Defensoria Pública do estado identificou sete comarcas onde não tramitaram processos relativos à violência contra a mulher nos anos de 2010 e 2011. Ainda segundo esse relatório, esses processos certamente existiram, mas não foram reconhecidos, porque tramitaram de outra forma ou como ações criminais, impossibilitando sua identificação (MINAS GERAIS, 2012). Embora ainda existam muitos entraves, alguns avanços podem ser apontados, por exemplo, a reestruturação dos boletins de ocorrência no estado, com a inserção de um campo objetivo para identificar se se trata de violência doméstica, evitando possíveis subnotificações.

Se, de um lado, é temeroso avaliar as políticas públicas e a atuação dos estados em relação à violência contra a mulher apenas a partir da perspectiva dos índices, de outro, é essencial monitorar a atuação do estado no que se refere ao investimento em infraestrutura para modificar a realidade e àquilo que propõe a legislação. A existência de instituições voltadas para o atendimento à mulher pode servir de accountability quando se discorre sobre a violência contra a mulher e a construção de sua cidadania. A complexidade do problema não pode dar margem à falta de monitoramento da atuação estatal. No que tange, sobretudo, à infraestrutura de atendimento à mulher em situação de violência, importantes questionamentos podem ser feitos ao Estado, a partir da perspectiva de que as novas instituições são importantes para reparar descompassos históricos que se espelham na realidade nacional. Como bem ressalta Oliveira (2010), atualmente, em vez de apenas focalizar-se como direitos legais, é certo que a cidadania também deve ser definida como um processo social pelo qual os indivíduos e os grupos sociais se ocupam reivindicando, expandindo ou perdendo direitos. Por isso, os dados da Pesquisa de 
Informações Básicas Estaduais do IBGE de 2012 e do Relatório Final da CPMI de 2013 acerca da situação da violência contra a mulher no Brasil são instrumentos valiosos para avaliar os avanços e expor a necessidade de cobrar dos governos. Nesse sentido, a seguir, procede-se à comparação quantitativa em relação aos equipamentos especializados de atendimento à mulher em situação de violência, a partir do cruzamento dos dados dos documentos suprarreferidos.

A Pesquisa de Informações Básicas Estaduais (IBGE, 2012) aponta a existência de 196 Delegacias Especializadas na região Sudeste, 40 na CentroOeste,61 na Nordeste, 47 na Norte e 51 na Sul. Hoje, pode-se falar em 299, uma vez que deste total, 28 do estado de São Paulo não são consideradas especializadas. Percebe-se, pois, tendência à redução da discrepância nos números de delegacias, que em 2012 se encontravam concentradas na região Sudeste.

Observa-se também um avanço quantitativo das delegacias especializadas. Contudo, uma boa parte dos estados registra o mesmo número, caso do Acre, com 2 para o Atendimento às Mulheres (DEAM), de Alagoas, com 3, da Bahia, com 15, do Distrito Federal, com 1, do Ceará, com 7, do Espírito Santo, com 10, do Mato Grosso do Sul, com,12, da Paraíba, com 9, do Rio Grande do Norte, com 5, e de Roraima, com 1. De outro lado, verifica-se a redução também desse quantitativo em alguns estados, segundo os dados analisados, caso do Amapá, Amazonas, Goiás, Pernambuco, Piauí e Sergipe (BRASIL, 2013).

Quanto aos Juizados Especiais, verifica-se que estes ainda não foram implementados em nove unidades da Federação (BRASIL, 2013), o que deve servir de pretexto para pressionar o Poder Judiciário, que tem competência para promover sua implantação, com base em previsão da Lei Maria da Penha, desde 2006.

Em Minas Gerais, a Lei Complementar 105 preconiza a implantação de nove Juizados Especiais, desde 2008 (MINAS GERAIS, 2012). Quanto à existência dos Conselhos da Mulher em Minas Gerais, dados de 2012 do IBGE apontam que grande parte dos 123 Conselhos concentra-se na região Noroeste.

A partir dos dados publicados no Relatório da CPMI de 2013 acerca da situação da violência contra a mulher no Brasil, foi possível identificar que a grande maioria dos estados brasileiros possui apenas uma Defensoria Pública da Mulher, destacando-se sua inexistência em Santa Catariana, Goiás e Mato Grosso. 
Em consonância com a análise aqui apresentada, torna-se essencial citar as conclusões da Pesquisa de Atuação do Poder Judiciário na Aplicação da Lei Maria da Penha promovida pelo Conselho Nacional de Justiça (CNJ) e divulgada em 2013. Nela, fazem-se importantes considerações acerca da distribuição das Varas e dos Juizados Especiais no Brasil. A conclusão a que chegou o CNJ é que essa distribuição é desproporcional, não obedecendo a critérios populacionais, ressalvando, ainda, que eles se concentram nas capitais e nas regiões metropolitanas (CNJ, 2013).

O Departamento de Pesquisas Judiciárias expõe que os tribunais com maior número de procedimentos são os do Rio de Janeiro, Rio Grande do Sul, Minas Gerais e Distrito Federal (CNJ, 2013). Nesse sentido, emitiu-se proposta de expansão da estrutura judiciária especializada no atendimento à mulher em situação de violência, a partir da implantação de novas Varas ou Juizados Especializados. As recomendações mais recorrentes referem-se ao estado de São Paulo, que deveria implantar mais cinco Varas/Juizados, seguindo-se Minas Gerais e Bahia, com quatro, cada um. A diretora executiva de pesquisas judiciárias do CNJ afirmou que em uma unidade especializada detentora de uma equipe multidisciplinar todos os atores que trabalham ali estão sensibilizados e envolvidos neste tipo de violência. Por isso, o processamento será melhor, por envolver menos tempo, e o cuidado será maior (PRADO, 2013).

Em consonância com o Relatório do CNJ, o Comitê para a Eliminação da Discriminação contra a Mulher (CEDAW, 2012) endossou o que apontam os documentos públicos, isto é, a dificuldade de implementação da legislação no que tange à violência contra mulher, defendendo a ampliação da estrutura judiciária como passo fundamental. Coloca-se como ponto a ser trabalhado pelo Estado o reforço de seu sistema judicial, para garantir que as mulheres tenham acesso efetivo à Justiça, traduzido pelo aumento do número tanto de tribunais como de juízes com expertise em casos de violência doméstica e familiar (CEDAW, 2012).

Reveste-se de grande importância discutir como se apresenta a estrutura político-administrativa das políticas para as mulheres no Brasil. O problema é complexo, assim como seus desdobramentos. Daí a necessidade de imprimir um pressionamento político. Considera-se primordial analisar como as políticas 
envolvendo as mulheres são tratadas e organizadas nas estruturas administrativas estatais.

As informações sobre a gestão da política de gênero constantes da Pesquisa de Informações Básicas Estaduais, de 2012, revelam que das 27 Unidades da Federação somente São Paulo não possui uma secretaria ou setor responsável por este tema. Identifica-se, também, que a maioria dos estados dispunha de órgão subordinado a outra política $(37,0 \%)$, mas parcela significativa tinha secretaria exclusiva $(33,3 \%)$. A gestão, para $18,5 \%$ dos estados, era realizada por outra secretaria ou setor não especificado. Para $11,1 \%$, ocorria na Secretaria de Justiça (IBGE, 2012). Como unidades da Federação com secretaria exclusiva para cuidar da Mulher, citam-se: Acre, Amapá, Maranhã, Sergipe, Pernambuco, Bahia, Rio Grande do Sul, Santa Catarina e Distrito Federal. Apresentavam secretaria estadual em conjunto com outra política: Tocantins, Paraíba, Alagoas, Paraná e Goiás. Dispunham de um setor subordinado a outra política: Rondônia, Amazonas, Roraima, Pará, Piauí, Rio Grande do Norte, Minas Gerais, Espírito Santo, Rio de Janeiro e Mato Grosso do Sul. Outra variação na estrutura configurava-se nos estados de Ceará e Mato Grosso, que possuíam um setor subordinado diretamente à chefia do Executivo (IBGE, 2012).

Dados da Secretaria de Políticas para as Mulheres ${ }^{5}$, apontam a presença de uma Secretaria Estadual exclusiva de Políticas para Mulher permanecem inalterados. Contudo, identificam-se, ainda, três secretarias estaduais não exclusivas de Política para a Mulher: uma vinculada à Diversidade Humana, na Paraíba; uma à Cidadania e Direitos Humanos, em Alagoas; e uma à Promoção da Igualdade Racial, em Goiás. Ressalta-se que o estado do Rio de Janeiro conta com uma subsecretaria estadual de políticas para mulheres e o Mato Grosso, uma superintendência. No estado de Rondônia, há a designação de um núcleo e em Tocantins, uma diretoria de assistência à mulher. Os demais estados, com exceção do Paraná, que não apresenta instituição com alcance estatal para abranger a temática, estruturam as políticas da mulher a partir de coordenadorias, caso de Minas Gerais (SPM, 2010). Evidentemente, a organização político-administrativa estatal, no que tange à mulher, não pode ser diretamente vinculada à efetividade da

\footnotetext{
${ }^{5}$ Disponível em: http://www.spm.gov.br/ Acesso em Julho de 2014
}

R. Inter. Interdisc. INTERthesis, Florianópolis, v.12, n.1, p.271-291 Jan-Jun. 2015 
política. Contudo, o que se defende é que, dada a própria fragilidade da cidadania feminina, a mulher torna-se parte em vários outros conflitos sociais.

Assim, a reestruturação político-administrativa seria primordial para lidar com a intersetorialidade das políticas, além de expandir os recursos políticos e financeiros para o empoderamento da mulher. Outros conflitos, como a dificuldade de acesso aos cargos profissionais de liderança pela mulher e a reminiscência de significativas diferenças salariais entre os homens e as mulheres, ilustram que a luta pela cidadania feminina vai além do combate à violência. Assim, as políticas para as mulheres devem estar articuladas com as políticas de trabalho e emprego e às políticas educacionais, por exemplo, integrando o que Nascimento (2010) denomina agenda coletiva.

A título de explicação, a atuação da SPM (2010) desdobra-se em três linhas principais de ação: a) Políticas do trabalho e da autonomia econômica das mulheres; b) Enfrentamento à violência contra as mulheres; e c) Programas e ações nas áreas de Saúde, Educação, Cultura, Participação Política, Igualdade de Gênero e Diversidade (SPM, 2013). Nesse sentido, também os governos estaduais devem se mobilizar para tratar as políticas das mulheres, considerando de forma mais expressiva seus desdobramentos. É inegável que o empoderamento da mulher e a plenitude de sua cidadania estão vinculados a muitas outras variáveis. Há de se falar, por exemplo, em emprego e em acesso à educação e à Justiça. Isso deixa evidente que, para trabalhar em rede, dada tal intersetorialidade, demanda-se dos governos promover uma reestruturação político-administrativa, para criar melhor divisão estratégica de políticas, articulação e fortalecimento político/orçamentário.

Em virtude da própria morosidade na implementação dos Juizados Especiais, endossa-se a importância de promover um pressionamento político ao Poder Judiciário. A restrição orçamentária, reiteradamente apontada pelos tribunais, não pode justificar o atraso de oito anos na construção de uma importante instituição para o acesso à Justiça pela mulher em situação de violência. De fato, a vontade política se impõe, reforçando a ideia de que a questão da violência contra a mulher carece de enfoque mais consistente. A deputada federal Jô Moraes cita como desafios no enfrentamento à violência contra a mulher: falta de pessoal para atender às ocorrências e falta de definição orçamentária (MINAS GERAIS, 2012). De fato, não há uma vinculação orçamentária para as políticas voltadas às mulheres. Com 
isso, os recursos ficam dependentes de árdua articulação política e do repasse federal, como expõe uma das entrevistadas da CEPAM.

Vale discutir que, apesar das críticas feitas, é importante refletir sobre o perigo de certos pleitos da sociedade. A restrição orçamentária assume grande influência quando se discutem as políticas públicas. Defender a existência de Delegacias Especializadas em cada município e apregoar o governo estadual como exclusivo deficitário pela consecução desse cenário são questões a respeito das quais não há consenso. Deve-se pensar de forma mais complexa as dificuldades que envolvem a administração pública, sobretudo a descentralização e a dificuldade de impor a execução de políticas no âmbito municipal. Membro da Comissão Especial de Violência contra a Mulher, a coordenadora do Pacto em Minas Gerais, representante do secretário da Secretaria de Estado da Saúde, no Relatório Final, afirma que é real a falta de comprometimento ou, mesmo, a resistência de muitos gestores municipais em levar a política de atendimento às vítimas para suas cidades (MINAS GERAIS, 2012).

De fato, chega-se a um cenário no qual se pode relacionar o município, como ente federado, sua autonomia financeira e a influência desses aspectos no combate a violência contra a mulher. Expõe, ainda, que, em se tratando do serviço psicossocial e jurídico,-quando gestores mostram que haverá aumento de custeio para a contratação, cria-se uma dificuldade muito grande em qualquer município (MINAS GERAIS, 2012). municípios que têm condições de arcar com os custos advindos da instalação de uma Delegacia Especializada. A implementação de mais equipamentos especializados no atendimento à violência contra a mulher é uma demanda legítima e urgente, mas deve ser feita de forma metódica e consciente, prevendo custos e sua sobrevivência. Levantamento produzido pela Pesquisa de Informações Básicas Municipais (MUNIC, do IBGE,2013) revela que a região Sudeste apresenta o menor percentual de prefeituras com estrutura de gestão da política de gênero: apenas $22,2 \%$.

Atualmente, menos de $10 \%$ dos municípios brasileiros conta com Delegacias Especializadas e pouco mais de um por cento com casas-abrigo. Se o número de equipamentos da rede aumentou nos últimos anos, essa evolução é tão lenta que, mantido o ritmo atual de abertura de serviços, serão necessários mais trezentos anos para que haja, pelo menos, uma Delegacia Especializada da Mulher por 
município e mais de mil anos para que cada um conte com um Juizado Especial ou vara adaptada (ANDREASSY, 2014, s.p.).

O Relatório Final da Comissão Especial de Violência contra Mulher, de 2012, aponta que em Minas Gerais, $40 \%$ dos municípios têm menos de 10 mil habitantes e não conseguem arcar com a construção e manutenção de um Centro de Referência. Por isso, foi preciso modificar a estratégia governamental, que passou a ser a de capacitar e qualificar os Centros de Referência de Assistência Social e os Centros de Referências Especializados de Assistência Social, para que tenham a condição de oferecer melhor atendimento à mulher vítima de violência.

No âmbito de Minas Gerais, devem-se reconhecer importantes avanços, como a criação do "Comitê Interinstitucional de Enfrentamento à Violência contra a Mulher", para o tratamento das políticas das mulheres de forma Intersetorial (MINAS GERAIS,, 2012, p.9). Esclarece uma das entrevistadas que o Comitê atua em questões de competência estatal no enfrentamento à violência contra mulher, envolvendo representantes da Polícia Civil, da Polícia Militar, da Secretaria de Desenvolvimento Social, da Secretaria da Educação, da Secretaria da Saúde e do Instituto Médico Legal.

Em contrapartida, como exposto na $23^{a}$ Reunião Extraordinária que debateu a criação de Juizados Especiais de Violência Doméstica e Familiar, com base na colocação das técnicas judiciárias que representavam o Tribunal de Justiça de Minas Gerais, específico de criação dos Juizados no estado.

O Juizado Especial, como defende a representante da Defensoria Pública de Minas Gerais, na mesma Reunião, é um instrumento importante de que o Estado dispõe para atender a mulher integralmente. Preconiza, em adição, que a mulher em situação de violência, normalmente, tem várias demandas, não apenas a relacionada propriamente à violência sofrida, desdobrando-se, assim, em questões civis, como divórcio, reintegração de posse e pedido de pensão. Assim, contar com um mesmo agente que desempenhe as funções de promotor, defensor e juiz favorece a solução do conflito de forma integral, permitindo, com isso, celeridade à causa feminina, reafirmando seu empoderamento e evitando seu desemparado diante da necessidade de buscar diversas varas até solucionar todas as demandas jurídicas.

R. Inter. Interdisc. INTERthesis, Florianópolis, v.12, n.1, p.271-291 Jan-Jun. 2015 


\section{CONCLUSÃO}

Este trabalho teve por objetivo explicitar o cenário das políticas públicas voltadas para mulher, a partir da perspectiva da análise dos entraves e dos avanços, especificamente, no que se refere ao enfrentamento à violência. Para isso, apoiouse em: informações disponíveis eletronicamente pela SPM, dados do Mapa da Violência 2012, Pesquisa de Informações Básicas Estaduais do IBGE de 2012, Relatório da CPMI de 2013 e Relatório Final da Comissão Especial da Violência contra a Mulher (MINAS GERAIS, 2012). A pesquisa a essas fontes permitiram concluir que o Pacto Nacional pelo Enfrentamento à Violência contra a Mulher e, no caso de Minas Gerais, o Plano Estadual de Políticas para as Mulheres representam um avanço para a construção da cidadania feminina.

Os resultados apontam para uma mudança do cenário nacional em relação às instituições de atendimento à mulher em situação de violência, a partir da comparação dos dados do IBGE de 2012 e do Relatório Final da CPMI de julho de 2013. Contudo, a cobrança ao Poder Público para imprimir maior celeridade à interiorização destas instituições é uma demanda legítima, sem prejuízo da reflexão acerca da intersetorialidade das políticas públicas, da dificuldade de descentralizar sua execução e, muitas vezes, da resistência municipal. Ainda é grande a defasagem quanto ao número e à distribuição dos serviços especializados de atendimento à mulher nas regiões brasileiras. Apontam-se, por exemplo: existência de estados com apenas uma Delegacia Especializada de Atendimento à Mulher; discrepância nos números de Centros de Referência; e reduzido número (ou ausência total) de Juizado Especial, Vara de Violência Doméstica e Familiar e Defensoria da Mulher na maioria dos estados. Tudo isso endossa que os eixos referentes à expansão da infraestrutura de atendimento à mulher em situação de violência o Pacto Nacional e ao Plano Estadual se defrontam com vários entraves, como: dificuldade de lidar com a descentralização, restrição orçamentária e fatores políticos próprios do cenário da administração pública.

Nesse sentido, apesar de algumas iniciativas incrementais, ainda há uma inegável carência na estrutura de enfrentamento à violência contra a mulher. $O$ Poder Legislativo promulga leis e recomendações que fortalecem a_cidadania 
feminina, mas o Poder Executivo representa sérias dificuldades para o cumprimento amplo dos direitos da mulher.

A contribuição do Pacto Nacional e do Plano Estadual para o enfrentamento da violência contra a mulher pode ser traduzida pelo fato de se constituírem como instrumentos essenciais para a orientação das políticas públicas, distanciando-se de ações pontuais e dispersas e caminhando para a consecução de ações mais articuladas, sobretudo após a criação do Comitê Interinstitucional. Contudo, a temática "Violência contra a mulher" carece de enfoque mais apurado, apesar do aumento dos recursos orçamentários após o Pacto Nacional.

A legislação, como fonte ativa do Direito, ainda não consegue vislumbrar um cenário de fortalecimento da mulher em sua plenitude. A falta de instituições para moldar um novo pensamento coloca-se como um óbice a essa pretensão. Oito anos depois de promulgada, a Lei Maria da Penha, ainda se apresenta como um processo em árdua construção. Nesse sentido, o Poder Público deve reafirmar à sociedade sua disposição de implantar Conselhos e demais instituições voltadas para a mulher, além de expandir o eixo de enfrentamento à violência nos Planos Estaduais, pois a violência contra a mulher é, sim, uma questão pública e, portanto, deve sofrer intervenções por parte dos órgãos governamentais competentes. 


\title{
CONSTRUCTION OF WOMEN'S CITIZENSHIP: CONTRIBUTIONS OF "THE NATIONAL PACT TO COMBAT VIOLENCE AGAINST WOMEN"
}

\begin{abstract}
Over the last few years laws and public policies have been developed to support women in building their status as citizens. However, advances in Brazilian legislation show us that they are no longer the formal aspects that inhibit women full process of citizenship. Thus, in this scenario it is important to discuss what are the improvements and challenges today for the implementation of the rights guaranteed by law. It is highlighted here the analysis of instruments promoted by the government through the policies and actions taken to guarantee the exercise of rights already provided by law. This article analyzes the main contributions of the National Pact to Combat Violence against Women and the State Plan of Policies for Women for the construction of female citizenship, in particular the plan adopted by the State of Minas Gerais, from the understanding that it should be constantly examined how federal entities are mobilized to the topic in question. The survey was exploratory in nature, developed from several sources. It concludes that although there are growing initiatives technical directives, there is still an undeniable fragility in the structure offered by the government to combat violence against.

Keywords: female Citizenship. Violence against women. National Pact to Combat Violence against Women. State Plan of Policies for Women. Framework to combat violence against women.
\end{abstract}

\section{CONSTRUCCIÓN DE LA CIUDADANÍA FEMENINA: APORTES DEL "PACTO NACIONAL POR LA LUCHA CONTRA LA VIOLENCIA CONTRA LA MUJER”}

\section{Resumen:}

Desde hace unos años han sido elaboradas leyes y políticas públicas para apoyar a las mujeres en la construcción de su condición de ciudadanas. Sin embargo, los avances en la legislación brasileña dejan claro que ya no son los aspectos formales los que inhiben el proceso completo de la ciudadanía para las mujeres. Por lo tanto, en este escenario, es importante hablar de lo que hoy son las mejoras y los retos que se presentan en la efectivación de los derechos garantizados por la ley. Se destaca aquí el análisis de los instrumentos promovidos por el Poder Público a través de las políticas y medidas adoptadas para garantizar el ejercicio de los derechos ya previstos por la ley. En este artículo se analizan las principales aportaciones del Pacto Nacional para Combatir la Violencia contra las Mujeres y el Plan Estadal de Políticas para las Mujeres para la construcción de la ciudadanía femenina, especialmente el plan adoptado por el estado de Minas Gerais, a partir del presupuesto de que se debería examinar constantemente cómo se movilizan los entes federales para el tema en cuestión. La investigación presenta un carácter exploratorio, y se desarrolló a partir de investigación documental, bibliográfica y de campo. Se concluye que, a pesar de algunas iniciativas de crecimiento gradual y la existencia de directivas, aún existe una innegable fragilidad en la estructura que ofrece el Poder Público para combatir la violencia contra las mujeres.

Palabras clave: Ciudadanía femenina. Violencia contra mujeres. Pacto Nacional para Combatir la Violencia contra las Mujeres. Plan Estadal de Políticas para las Mujeres. Estructura para combatir la violencia contra las mujeres. 


\section{REFERÊNCIAS}

ANDREASSY, Érika. Sem dinheiro, políticas públicas de combate à violência contra mulheres ficam comprometidas. [S.I.], 2014. Disponível em:

http://www.pstu.org.br/node/20433. Acesso em: 10 jun.2014.

ARENDT, Hannah. The origins of totalitarianism. Nova York: Harcourt Brace Jovanovitch, 1993.

BENEVIDES, Maria Victória. O que é formação para a cidadania? São Paulo, 2000. Disponível em: http://www.dhnet.org.br . Acesso em: 10 jun. 2014.

BICEGLIA, Tânia Regina. A mulher e a evolução histórica de suas conquistas na legislação civil e constitucional brasileira. Monografia. Faculdade de Direito de Presidente Prudente. São Paulo, 2013. Disponível em: http://intertemas.unitoledo.br/revista/index.php/Juridica/article/viewFile/47/55 Acesso em 10 de jun. 2014.

BRASIL. Convenção Interamericana para Prevenir, Punir e Erradicar a Violência contra a mulher. Belém do Pará, em 9 de junho de 1994. Disponível em: http://www.cidh.org/Basicos/Portugues/m.Belem.do.Para.htm . Acesso em: 11 jun. 2014.

BRASIL. Constituição da República Federativa do Brasil. Brasília, 1988. Disponível em: http://www.planalto.gov.br/ccivil 03/constituicao/constituicao.htm. Acesso em: 10 jun. 2014.

BRASIL. Lei 11.340 - Lei Maria da Penha. Brasília, agosto 2006. Disponível em: http://www.planalto.gov.br/ccivil 03/ ato2004-2006/2006/lei//11340.htm. Acesso em: 11 jun.2014.

BRASIL. Secretaria de Políticas para as Mulheres da Presidência da República.

Pacto Nacional pelo Enfrentamento à Violência contra a Mulher, 2007. Disponível em: http://mulheres.gov.br/assuntos/violencia/pactonacional/Pacto\%20Nacional. Acesso em: 26 fev .2015.

BRASIL. Senado Federal. Relatório Final da Comissão Parlamentar de Inquérito acerca da situação da violência contra a mulher no Brasil. Brasília, 2013. 
Disponível em: http://pt.slideshare.net/BlogDoPlanalto/relatrio-final-da-cpmi-sobreviolncia-contra-mulher. Acesso em: 08 jun. 2014.

CEDAW. The United Nations Committee on the Elimination of Discrimination against Women. Concluding observations of the Committee on the Elimination of Discrimination against Women.[s.l.], 2012. Disponivel em: http://acnudh.org/wpcontent/uploads/2012/03/CEDAW-2012-English-advanced-unedited-version.pdf. Acesso em: 05 jun. 2014.

CNJ. A atuação do Poder Judiciário na aplicação da Lei Maria da Penha, Brasília, 2013. Disponível em: http://www.cnj.jus.br/images/programas/lei-maria-dapenha/cartilha maria da penha.pdf. Acesso em: 26 fev. 2015.

FJP. Análise do Perfil dos Representantes Eleitos nas Assembleias Legislativas Brasileiras. Belo Horizonte, 2013. Disponível em: http://www.eg.fjp.mg.gov.br/index.php/docman/publicacoes-2013/134-analise-doperfil-dos-representantes-eleitos-nas-assembleias-legislativas-brasileirasnovapublicacao/file . Acesso em: 26 fev. 2015.

IBGE. Censo Demográfico 2010 - Resultados do universo. Disponível em: http://www.ibge.gov.br. Acesso em: 20 jun. 2014.

IBGE. Pesquisa de Informações Básicas Municipais - MUNIC . Brasília, 2013. Disponível em: ftp://ftp.ibge.gov.br/Perfil Municipios/2013/munic2013.pdf. Acesso em: 10 jun.2014.

IBGE. Pesquisa de Informações Básicas Estaduais. Brasília, 2012. Disponível em: ftp://ftp.ibge.gov.br/Perfil Estados/2012/estadic2012.pdf. Acesso em: 05 jun.2014.

IPEA. Violência contra a mulher: feminicídios no Brasil, 2013. Disponível em: http://www.ipea.gov.br/portal/images/stories/PDFs/130925 sum estudo feminicidio leilagarcia.pdf. Acesso em: 26 fev.2015.

MARSHALL. T.H. Cidadania, Classe Social e Status. Rio de Janeiro, Zahar editores. 1967.

MINAS GERAIS. Assembleia Legislativa de Minas Gerais. Políticas Públicas ao seu alcance. Mulher. Dados e Indicadores. (site oficial) Disponível em: 
http://politicaspublicas.almg.gov.br/temas/index.html?tagNivel1=295\&tagAtual=1019 ‥ Acesso em: 26 fev.2015.

MINAS GERAIS. Assembleia Legislativa de Minas Gerais. Relatório Final da Comissão Especial da Violência contra a Mulher. Belo Horizonte, 2012. Disponível em: http://mediaserver.almg.gov.br/acervo/41/710041.pdf. Acesso em: 10 jun. 2014.

MINAS GERAIS. Lei Complementar $\mathbf{n}^{\circ}$ 105. Belo Horizonte, 14 de agosto de 2008. Disponível em:

http://www.tjmg.jus.br/data/files/6C/C5/AC/6C/9847A310B895B6A3180808FF/lei co mplementar 105 consolidado.pdf. Acesso em: 26 fev.2015.

MINAS GERAIS. Secretaria de Estado de Trabalho e Desenvolvimento Social SEDESE. Plano Estadual de Políticas para Mulheres. Belo Horizonte, 2014.

OLIVEIRA, Paula Julieta Jorge de. A Cidadania é para todos. Direitos, deveres e solidariedade. Jus Navigandi, Teresina, ano 15, n. 2517, 23 maio 2010. Disponível em: http://jus.com.br/artigos/14885. Acesso em: 10 jul. 2014.

PRADO, Débora. Lei Maria da Penha: varas exclusivas aumentam a credibilidade do Judiciário e encorajam denúncia. São Paulo, 2013. Disponível em: http://www.compromissoeatitude.org.br/lei-maria-da-penha-varas-exclusivasaumentam-a-credibilidade-do-judiciario-e-encorajam-a-denuncial. Acesso em: 26 fev. 2015.

SOARES, V. Projeto Vila-Bairro: Impacto nas Relações de Gênero. In: Governo Local e Desigualdades de Gênero. Estudos apresentados pela FGV-EASP, Hewllett, Fundação Ford e AGENDE. São Paulo, 2002.

Artigo:

Recebido em 31.07.2014

Aceito em 04.03.2015 